\title{
STRUCTURAL MODELS FOR PROVINCIAL NURSING COLLEGES
}

\author{
LR Uys, University of KwaZulu-Natal
}

\begin{abstract}
The public Nursing Colleges are interested in becoming Higher Education Institutions in order to be able to offer the new qualifications gazetted by the SANC. If they become part of the subsidy system of the Department of Higher Education and Training, it is important to understand what the implications are for their funding. The aim of this article is to explore the impact on College finances if they become registered Higher Education Institutions (HEls) and move to the subsidy system.
\end{abstract}

A survey was done of four colleges representing three provinces to establish their current funding and student group. It was then calculated what their subsidy would have been in the same year if they were in the higher education system. It was found that some of the colleges would have done better and some worse in a new system. This variation exists even between the two colleges from the same province.

It is recommended that nursing colleges become part of the HEMIS system and that a norms-based funding system be developed and implemented. It is also recommended that a more appropriate fee structure be developed for nursing students at Nursing Colleges.

\section{Keywords:}

\section{Introduction}

Nursing education was historically initiated by hospitals who trained for their own staffing needs. They usually followed the apprenticeship model, with theoretical teaching first being done on a limited basis by hospital staff, both doctors and nurses. Gradually, teaching staff were appointed and teaching centres developed. The first independent nursing college, Carinus Nursing College, was established in Cape Town in 1949. The student nurses from this college were placed in a range of hospitals in the peninsula for their clinical training, but received their theoretical education at the College. However, this pattern was discontinued in the 1960s and hospitals again took over their own training.

Over the last thirty years, the apprenticeship model was replaced internationally by the higher education model (Mannix et al., 2009). In this model, nursing programmes are offered by institutions of higher education such as universities and colleges, which arrange for clinical training together with health services in their community. This also happened in South Africa, with nursing colleges being established to offer nursing education in the 1980s. This did not mean that all hospital schools were abolished. Many of them kept on offering certain programmes, sometimes independently and sometimes as part of a college network. Each of the nine provinces in the country has at least one public nursing college or school. 
The nursing education system of a country has to

- Address the workforce needs of the country (a workforce requirement);

- Give equal access to education to everybody (a social responsibility requirement);

- Provide good quality education (equal quality) in all components of the system (a workforce and social responsibility requirement).

These are the criteria against which the structure of the public provincial nursing college sector in South Africa will be evaluated. Structure refers to the type of campus (single or multiple) and the site of the campus(es) (centralized or decentralized).

\section{Literature Review}

Multiple campuses are increasingly becoming a feature of higher education internationally (Chen, 2013) and in South Africa (Kamsteeg, 2008), mainly due to the merging or growth of existing institutions. Multi-campus higher education institutions may offer educational programmes in a sequential manner, with students studying certain components on one campus and others on another, or in a parallel manner, with the whole programme being offered on each campus (Harrison et al., 2010). The management system may also differ, with some institutions having relatively independent campus management, such as the North West University, and others having a centralized system that limits duplication across campuses, such as the University of KwaZulu-Natal (Kamsteeg, 2008).

Harrison et al. (2010) investigated multi-campus pharmaceutical education in the USA and listed the following benefits or reasons for multiple campuses:

- The number of graduates can increase due to hospital or clinical resources being increased, thus addressing workforce needs;

- Such campuses facilitate inter-professional activities for students;

- Student opportunities and experiences are enhanced, including choice of campuses, smaller class sizes and flexibility in teaching approaches;

- Enhanced use and number of clinical training sites and teaching by potential teachers not on the main campus;

- Offer a range of benefits for the region in terms of distributing public resources, services and educational opportunities;

- Increase student recruitment from underserved areas and groups, thereby enhancing student diversity;

- Opportunities for cost efficiencies, including resource sharing and need for fewer faculty members;

- More opportunities for industry or community/university partnerships;

- Alternative space can be used, or spaces that are more easily available;

- Takes a regional approach to higher education, rather than focusing on one or two cities. 
However, authors also list the following problems (Nicolson, 2004; Chen, 2013 Gallifa, 2009 \& Harrison et al., 2010):

- Problems with effective and efficient communication between campuses for staff and students;

- Inability to provide equivalent services/experiences to all campuses for staff and students;

- Different cultures and focus at different campuses, leading to lack of cohesion;

- Different outcomes from different campuses;

- Difficulty with standardization of operations between campuses;

- Greater need for improved physical facilities such as transport, especially at rural campuses;

- Travel between campuses are stressful and time-consuming;

- Difficulty to recruit and retain faculty, leading to higher workloads on some campuses;

- Negative attitudes within and between campuses, feelings of inequality (real or imaginary);

- Inconsistent student outcomes between campuses.

In terms of addressing workforce needs and providing equal access to education for everybody in the country, the issue of rural education institutions is a major issue in the literature. Rural areas are defined differently by different authors, but the Australian classification of rural areas is most useful (see table 5.1). They further distinguish between levels of urban and rural spaces, so that their classification finally has seven categories. Van Hofwegen et al. (2005) define a rural area as one more than $80 \mathrm{~km}$ from a major regional hospital and with a population of less than 10000 .

Table 5.1: Classification of rural and urban areas*

\begin{tabular}{|l|l|}
\hline Category & Population \\
\hline Metropolitan & $\geq 100000$ \\
\hline Rural & 10000 to 99999 \\
\hline Remote & $\leq 9999$ \\
\hline
\end{tabular}

*Gum, 2007, adapted from Australian Department of Health and Aging Review of Rural, Remote and Metropolitan Areas (RRMA) Classification Discussion Paper 2005.

The centralization of health professional education in urban areas has characterized not only nursing, but also medical and dental education. In medical education this has led to a model of education characterized as hospital and specialist-centred (Maley, Denz-Penhey, Lockyer-Stevens \& Murdoch, 2006). Nursing education remained more active in rural areas, if these are defined as schools outside either the largest or the two main cities of a province with, for instance, the Eastern Cape in South Africa having 28 nursing schools outside the metropolitan Port Elizabeth urban area, and the Free State having 11 such schools outside Bloemfontein (SANC, 2013). Most of these sites offer pre-registration education. The limitations of an urban-focused health professional education system emerged gradually and, in the 1990s, different international organizations such as the World Health Organization (WHO) and countries such as Australia adopted policies trying to strengthen rural education (Eley 2012, Strasser \& Neusy, 2010).

Initially, the motivation behind rural education for health professionals (or rural campuses attached to urban institutions) was to address the shortage of health workers in rural areas. In South Africa, $39.3 \%$ of the population or more than 19 million people live in rural areas (World Bank, 2012). They need health services to be delivered to them in these areas, but it is difficult to recruit and retain well trained professionals in these services. The South African Department of Health (DOH) reported that only $12 \%$ of medical practitioners and $19 \%$ of nurses practise in rural areas (DOH, 2011). It has 
been proven that if one recruits students from rural areas and trains them in here, then they are more likely to remain working in such areas. For instance, a study in Australia showed that nurses from rural schools deliver a higher proportion of rural-working graduates because graduates from these schools have rural-readiness (Playford, Wheatland \& Larson, 2010). Some local studies confirm this finding, although they refer to medical and dental students and not to nursing students (de Vries \& Reid, 2003; Couper et al., 2003).

Another reason why rural education is important for health professionals is that rural practice differs from urban practice, and students have to be specifically prepared to practice in country areas. Strasser and Neusy (2010: 777) point out that, "When compared to their metropolitan counterparts, rural practitioners (of all professions) carry a heavier workload, provide a wider range of services and carry a higher level of clinical responsibility". With regard to nursing, van Hofwegen, Kirkham and Harwood (2005) argue that rural practice demands greater autonomy from nurses in terms of independent decision-making, an expanded breadth of practice and a greater interdisciplinary role. Rural practice is also more involved with relationships, gives a greater understanding of community and teaches the nurse to work with limited resources. Rural practice demands a multi-skilled generalist able to adapt easily and see hardship as an opportunity for growth (Kenny \& Duckett, 2003; Longenecker, Zink \& Florence, 2012).

Another driver for rural education and multiple campuses has been the increase in numbers of health professionals being trained, and the need to use rural health facilities to accommodate these larger numbers (Maley, Worley \& Dent, 2009). In their Human Resources Strategic Plan of 2011, the $\mathrm{DOH}$ also envisages an increase in the number of nurses being trained, and it is therefore important to keep rural healthcare settings as training sites.

The health of rural populations is generally poorer than that of people living in urban areas (Kenny and Duckett, 2003) and rural populations also have fewer resources, a lower standard of education and a higher rate of unemployment and poverty. There is some evidence that the presence of institutions of higher education preparing health professionals in a rural area improves health indicators. For instance, a medical school was established in a rural province of the Philippines and within twelve years the infant mortality rate in the province decreased by $90 \%$ (Christobal \& Morley, 2012). Gibb (2004) also points out that the availability of "incremental learning" programmes in rural areas provides access to higher education for rural people. Incremental learning is a ladder approach to qualifications; for instance, a certificate giving access to diploma training and then to degree training.

The issue of quality education also needs to be addressed in this debate. Models for exposure of undergraduate students to rural practice varies from day visits to rural settings from urban schools through to a range of shorter and longer exposure options to establishing rural schools where the whole qualification is obtained in a rural setting (Maley, Worley \& Dent, 2009). 
From the literature, the following criteria seem to play a role in establishing good quality and effective rural health professional education (Downey et al., 2010; Kruger \& Tennant, 2010; Strasser \& Neusy, 2010; Eley et al., 2012):

1. Recruit the right students: those from a rural background are more inclined to return to such settings after completion of their training.

2. Ensure a positive clinical and educational experience in the rural setting. This involves meeting the placement expectations of the students and developing a strong supporting social structure in the rural setting.

3. Ensure a cadre of strong rural professionals to act as role models and mentors and focus on establishing a workplace culture that is supportive of learning.

4. Put in place effective support systems. These include financial and logistic, (accommodation and travel), as well as safety and educational support. Students in rural settings often feel isolated from information and people at the central campus (Gum, 2007).

5. Develop an appropriate curriculum which is focused on generalist practice, wide-ranging assessment skills and high-level emergency response skills (Jukkala, Henley \& Lindeke, 2008). Without a rural-focused curriculum, students are left with a feeling of inadequacy and lack of confidence and comfort (Leipert \& Anderson, 2012).

6. Evaluate the programmes comprehensively and regularly and make changes if necessary. For instance, Gibb (2004) found that in some rural healthcare settings which were not geared to being educational environments, a reticence to learn, inertia in relation to self-directed learning, and a sense of imposed change interfered with the learning of students.

The two most common approaches to using technology to enhance the quality of rural education are video conferencing and computer assisted learning. Videoconferencing is dependent on high speed Internet access at rural sites which may be a problem in developing countries. "Computer-supported collaborative learning" can best be understood by analyzing the constituent elements of the term. "Computer-supported" means that computers are at the centre of the learning environment, although this does not necessarily mean a traditional PC. Mobile phones, GPS-enabled handheld devices, or computers have all been used to support CSCL. This support can either involve students working together in front of a computer with the computer acting as a tool to support face-to-face collaboration, or the students can work from a distance and use computers or other devices as mediation tools for communication, as places to organize their learning, or as authoring tools for building knowledge representations together (such as concept maps or essays). "Collaborative learning" means more than just dividing up an assignment and piecing it together at a later time, or what students often call "divide and conquer". Better termed "cooperative learning", it does have a place in higher education. For learning to be collaborative, however, students need to work with each other to solve problems. This means that they need to recognize conflicting claims, weigh evidence and argue their positions with each other in order to negotiate meaning. In doing so, they collaborate to solve problems, build products or create knowledge (Porcaro \& Al Musawi, 2011).

In conclusion, then, the literature indicates that rural education sites are an important part of the health professional education system both in terms of numbers and access, but that such learning environments need to be managed in a manner that ensures quality. 


\section{Models of Nursing Education}

Two distinct models for the organization of public nursing colleges have developed in this country since the 1980s and are described below. They might not be totally typical in every province, but the provincial examples give a flavour of each model. A third model, not used in South Africa, but which is employed in other countries, is also described.

\section{The centralized model}

In two provinces (Gauteng and the Western Cape), a centralized model was chosen. This is characterized by large colleges (only one in the case of the Western Cape) in urban areas, which offer all the programmes centrally. Each of these large colleges has its own governance system and infrastructure. However, there has been some debate about whether the large colleges in Gauteng should be merged so that only one council and one governance structure would be necessary. These centralized colleges are mainly single-campus colleges, although they might use clinical facilities over a large geographical area.

\section{Advantages:}

1. Large groups of students in each programme allow for a more economical delivery of educational programmes. Instead of having to teach two classes with 20 students in each, in these colleges 40 students can be taught by one lecturer.

2. The provision of services such as libraries and clinical and anatomy/physiology laboratories can be done more economically, since one facility will serve a large number of students.

3. Centralizing services also allows for a better quality of training. For instance, if one has to staff only one library instead of ten, one can afford a fully qualified librarian, something that might be difficult for each small decentralized library.

4. It is easier to recruit and retain academic staff in cities rather than in rural areas, especially those in more remote parts. This also means that the quality of staff recruited might be higher, since there is more competition for the posts.

\section{Disadvantages}

All the benefits listed under the decentralized model are missing in this model.

1. Rural health services may fail to attract staff trained in the cities, thus making staffing in health services in rural areas problematic;

2. Rural health services have less access to teaching and learning resources, thus gradually decreasing the quality of care in these settings;

3. Students from rural areas might find it difficult to access urban training schools for a variety of socio-economic reasons, thus limiting the pool of nursing recruits;

4. Since rural health services are not used for training, the potential learning of students in this kind of health services is excluded. Since $39.3 \%$ of the South African population lives in rural areas, not preparing nursing students to work in such settings does not qualify as appropriate education.

5. The health services in cities may be over-populated with students, leading to less than ideal clinical experience.

\section{The decentralized model}

In two provinces (KwaZulu-Natal and the Eastern Cape) a decentralized model was chosen. This is characterised by one large college with many delivery sites, called either campuses or sub-campuses. The single college has one central administrative office, usually one College Council and one Senate. 
Each campus or sub-campus has a principal and offers some, but not all programmes, depending on the service and academic capacity. Generally, larger campuses offer more complex programmes, such as the four-year Diploma or Specialist Nurse education, while smaller campuses concentrate on auxiliary and enrolled nurse training. For instance, the KZN Nursing College has a central administrative office, eleven campuses and fourteen sub-campuses.

\section{Advantages:}

1. It is generally believed that a health service where nurses are trained, delivers better care than those where training does not take place. The involvement in training of a large number of hospitals and clinics spread over the province should therefore increase the quality of care in the province.

2. The decentralized campuses may allow for greater access to training for rural school leavers and nurses, since they can study from home. This, however, depends on the selection criteria of the centralised colleges, which might use quotas from different areas.

3. The decentralized training should also increase the chances of rural health services being able to recruit the students who qualify and to retain their services. This does not mean that qualified nurses will remain in the first position they hold after training, but even if they move to an urban area at a later stage, they would at least have provided some service in a rural setting.

4. The teaching-learning resources of the college can be an important resource for decentralized health services. The library could be multi-disciplinary, and the nurse educators could assist with continuing professional development of the nursing staff.

Disadvantages

1. The cost of this model is a disadvantage. Intakes of students in these campuses are generally limited to about 30 students, due to limited physical classroom space and also, perhaps, to limited clinical teaching material. It is increasingly understood that large student groups such as 100 or more are possible if appropriate teaching and learning strategies are used and adequate equipment is available. The small campuses do not allow for economies of scale to reduce cost.

2. It is difficult to recruit high quality academics to distant campuses. The result is that one either has a fast turn-over of staff, with little stability, or one makes do with inadequately prepared staff, since they are all that is available.

3. It is difficult to create an education brand for these small campuses hidden in rural hospital grounds. They seldom have custom-built educational buildings, and the physical facilities are often less than optimal. 


\section{The mixed model}

The mixed model has not been implemented in South African nursing education, but is well described in the literature. It is characterized by centralized teaching with shorter or longer rural placement. It usually goes hand-in-hand with high technology approaches such as computer-assisted education and video conferencing in order to deliver teaching and learning. The decentralized sites are equipped with excellent learning facilities, mainly electronic and simulation-based, and appoint local mentors to support students. Students have direct access to teaching and learning resources at central campuses through Internet access. The teaching approach will be a blended approach (combining face-to-face with computer-based teaching) incorporating high levels of self-directed learning.

Each smaller campus usually has dedicated learning spaces where students will have access to computer-based learning exercises, an electronic library, e-books, low fidelity models for anatomy and clinical nursing teaching, and books. For examples of such learning spaces, see "Learning Spaces" on the website of "educause". The campus also has clinical preceptors who do the teaching and supervision during clinical practice. The centralized campus provides the necessary IT technicians, who will also be responsible for maintaining equipment and systems in the attached sub-campuses.

The Australian system provides a good example of this approach. In 2001, the government launched an initiative to promote rural education of health professionals by creating Rural Clinical Sites (RCSs) where students in the health professions at urban institutions spent time during their training. Fourteen such RCSs now exist and there are a number of descriptions in the literature of how they are developed and used (Eley et al., 2012; Gum, 2007).

\section{Advantages:}

1. All the advantages of the decentralized model are maintained.

2. Creating such high-tech learning spaces on all campuses will revolutionize the teaching and learning in the College, since this system demands a new orientation from educators and students alike.

3. It is an interactive, student-centred approach to teaching and learning which is in tune with today's generation of students. The CSCL and blended approaches are the most effective methods currently available (Cavanagh, 2011).

\section{Disadvantages:}

1. It will cost a significant amount of money to create the appropriate learning spaces on decentralized campuses. Without a strong logistic, educational and social base, rural placement may be a stressful experience for students, leading to poor learning (Strasser \& Neusy, 2010).

2. The nurse educators of the College will have to go through a thorough development programme and be assisted to develop appropriate teaching/learning material and to use appropriate methods.

3. The students will need computer training and courses will have to be gradually developed and adapted to become most efficient (Porcaro \& Masawi, 2011). 


\section{Conclusion}

It may look like an easy option to centralize nursing education, as has been done in medical, pharmaceutical and allied health education in this country. However, in the long term, urban areas do not have enough health services to prepare nurses for the whole population, and the limited recruitment pool also reduces the human resources for nursing. In a country with a large rural population, it is also important for nurses to be able to practise confidently in more isolated, less supported health settings. It is almost impossible to prepare people for such settings in urban, hightechnology, well-staffed health services.

The current rural schools suffer from many problems (see chapter 6), especially with regard to learning resources and well-qualified teaching staff. If one accepts such problems as "given", you also have to accept an inferior quality of nursing education and sub-standard health services for rural areas. This is contrary to the constitution of this country, which is a human rights-based document and demands equal rights for all citizens.

It would seem that a mixed model is most advantageous in most cases, since it allows for all three objectives (quantity, access and quality) to be achieved. This is also a model that makes use of the latest technologies available in higher education and invests in technology that can be updated and moved. It is doubtful whether even with the other two models a low-technology environment is sustainable into the future, since it is not consistent with current teaching-learning approaches and student skills and expectations.

The Independent Lancet Global Commission on Health Professional Education for the Next Century (2010) advocates strongly for transformative education, which they define as education aimed as informing (teaching information and skills), but also forming (socializing and transmission of values) and finally also transforming (creating leaders). The report stresses that this is only possible if institutions change and educators become leaders in this third generation reform.

\section{References}

Cavanagh, T. B. 2011. The blended learning toolkit: Improving student performance and retention. Educause Review Online 34(4): Online

Chen, F.L. et al. 2010-. Health professionals for a new century: transforming education to strengthen health systems in an interdependent world. www.thelancet.com (DOI:10.1016/S0140-6736(1)18545)

Chen, J. 2013. Strategies study on how to achieve good teaching quality for teachers in multi-campus education. Asian Social Science 9(7): 279-282.

Christobal, F. \& Worley, P. 2012 Can medical education in poor rural areas be cost-effective and sustainable: the case of the Ateneo de Zamboanga University School of Medicine. Rural and Remote Health 12: 1835 (online) www.rrh.org.au

Couper, I. D., Hugo, J.F.M., Conradie, H. \& Mfenyana, K. 2003. Influences on the choice of health professionals to practice in rural areas. South African Medical Journal 97(10): 1082-1086.

Department of Health 2011. Human Resources for Health South Africa HRH Strategy for the Health Sector 2012/13- 2016/17. www.http//psyssa.com/documents/HRH\%20-\%20Strategy.pdf. 
De Vries, E. \& Reid, S. 2003. Do South African medical students of rural origin return to rural practice? South African Medical Journal 93(10): 789-793.

Downey, L. H., Wheat, J. R., Leeper, .J D., Florence, J. A., Boulger, J. G. \& Hunbaker, M. L. 2010. Undergraduate rural medical education program development: focus group consultation with the MRHA Rural Medical Educator Group. Journal of Rural Health 27: 230-238.

Eley, D. S., Synnot, R., Baker, P. G. \& Chater, A. B. 2012. A decade of Australian Rural Clinical School graduates - where are they and why? Rural and Remote Health 12: 1937 (online) www.rrh.org.au

Gibb, H., Anderson, J. \& Forsyth, K. 2004. Developing support for remote nursing education through workplace culture that values learning. Australian Journal of Rural Health 12: 201-205.

Gallifa, J. 2009. Professional integration in higher education: a methodological approach applied to a multi-campus university in Spain. Journal of Higher Education Policy and Management 31(3): 229 237.

Harrison, L.C., Congdon, H.B. \& DiPiro, J.T. 2010.The status of US multi-campus colleges and schools of pharmacy. American Journal of Pharmacutical Education 74(7): 1-6.

Jukkala, A. M., Henley, S. J., \& Lindeke, L. L. 2008. Rural perceptions of continuing professional education. Journal of Continuing Education in Nursing 39(12): 555-563.

Kamsteeg, F. 2008. In search of a merged identity: the case of multi-campus North West University, SA. TD 4(2): http://hdl.handle.net/10394/3939.

Kenny, A. \& Duckett, S. 2003. Educating for rural nursing practice. Journal of Advanced Nursing 44(6): 613-622.

Kruger, E. \& Tennant, M. 2010. Short-stay rural and remote placements in dental education, an effective model for rural exposure: A review of eight-year experiences in Western Australia. Australian Journal of Rural Health 18: 148-152.

Leipert, B. \& Anderson, E. 2012. Rural nursing education: a photovoice perspective. Remote and Rural Health 12: 2061 (online) www.rrh.org.au

Longenecker, K., Zink, T. \& Florence, J. 2012. Teaching and learning resilience: Building adaptive capacity for rural practice. The Journal of Rural Health 28: 122-127.

Maley, M. A. L., Denz-Penhey, H., Lockyer-Stevens, V. \& Murdoch, J. C. 2006. Tuning medical education for rural-ready practice: designing and resourcing optimally. Medical Teacher 28(4): 345350.

Maley, M., Worley, P. \& Dent, J. 2009. Using rural and remote settings in the undergraduate medical curriculum: AMEE Guide No.47. Medical Teacher 31: 969-983. 
Mannix, J., Wilkes, L. and Luck, L. 2009. Key stakeholders in clinical learning and teaching in Bachelor of Nursing programs: A discussion paper. Contemporary Nurse 32 (1-2): 59-68.

Nicolson, R. 2004. The management of multicampus systems. S A Journal of Higher Education 18(2): 346-358.

Oblinger, D.G. 2006. Learning Spaces. www.educause.edu/learningspaces

Playford, D., Wheatland \& Larson, A. 2010. Does teaching an entire nursing degree rurally have more workforce impact than rural placement? Contemporary Nurse 35(1): 68-76.

Porcaro, D. S. and Musawi, A. S. 2011. Lessons learned from adopting Computer-Supported Collaborative learning in Oman. EUCAUSE Quarterly. Online access

Strasser , R. \& Neusy, A. J. 2010. Context counts: training health workers in and for rural and remote areas. World Health Organization Bulletin 88: 777-782.

Van Hofwegen, L., Kirkham, S. \& Harwood, C. 2005. The strength of rural nursing: Implications for undergraduate nursing education. International Journal of Nursing Education Scholarship 2(1): 1-13

World Bank 2012. Rural populations. data.worldbank.org/indicators/SP.RUR.TOTL Accessed: 13 October 2012. 
Harrison, L. C., Congdon, H. B. \& Dipiro, J. T. 2010. The Status of US Multi-campus Colleges and Schools of Pharmacy. American Journal of Pharmaceutical Education, 74, 1-6. 